\title{
Dark Places: Environmental Education Research in a World of Hyperobjects
}

Authors: Saari Antti, Mullen John

\section{Abstract}

Escalating ecological events like global warming haunt our lived experience of place and demand thinking the concept anew in environmental education research. Using Timothy Morton's notions of hyperobjects and dark ecology as a springboard, we articulate the uncanny_-the withdrawn, unknowable, excessive and anxiety-provoking-aspects of place that events like global warming disclose for place-based pedagogies. Given the advent of hyperobjects as a theoretical model coupled with the ontological and ethical attunement of dark ecology, we suggest conceptualizing place through the strategies of juxtaposition and working-through in order to begin thinking through the implications of how to live in dark places that are haunted by the reality of hyperobjects.

Keywords: environmental education research, place-based pedagogy, uncanny, global warming, hyperobjects

\section{Introduction}

Recent discussions converging around post-structuralism and new materialism in environmental education research problematize place as a foundation of meaning-making experienced as present, familiar and knowable. Escalating ecological events have made it increasingly difficult to think about place in terms of belonging and dwelling 'in' an 'environment', 'nature' or 'world' without acknowledging the gaps, disparities and lines of 
flight therein. Instead, concepts and metaphors of becomings, paths and networks have been mobilized to open novel vistas for thinking about places as unbounded, non-present and inherently unknowable (see e.g. Clarke 2017; Nakagawa \& Payne 2014). In an effort to partner with these problematizations of place in environmental education research, we attempt to highlight the uncanny abjection that haunts places both within and without.

Consider for example the advent of global warming: we can experience its effects and compute its existence, yet we are unable to point to it in any meaningful sense as if it exists hauntologically; that is, producing spectral effect that are both present and yet absent as if inhabiting our climatic systems disrupting and distabilizing them and consequently producing an uncanny aspect to our experiences of place (Caputo 2016b, 116-120).

This uncanny aspect became visceral on the morning of October 17th, 2017 in southern Finland when the rising sun was exceptionally red, and this, we were told, was due to the sands of the Sahara and the fine particles from the Portuguese forest fires that hurricane Ophelia carried to the Irish coast and then over Finland. These particles filtered out blue light from the sun and left only red hues. Was this singular moment haunted by the specter of global warming? Our guesses can only be probabilities as we cannot see the relation between the red sunrise and global warming in any causal sense; nor can we capture it in any distinct geographic location: it is, in short, non-local and phased, aspects among others, which we will explore in greater detail below. Moreover, in an uncanny way, global warming is also ‘in’ us: it is inside our thoughts, our ways of life and the objects we engage with daily; and therefore, it is impossible to externalize in our traditional spatial categories like 'nature' or the 'environment'. The event of global warming, in short, does something to places that our concepts of it are not prepared for: it haunts. 
Foregrounding global warming as a case example, we use Timothy Morton's concepts of dark ecology and hyperobjects to tease out the uncanniness involved in thinking about placebased pedagogies without the symbolic support of 'place', 'nature' or 'world' that have aided in compartmentalizing ecological phenomena and awareness into cultural and natural, local and global and human and non-human categories. We argue that thinking about dark ecology and hyperobjects aids in articulating the dimension of the uncanny in place-based pedagogy. We suggest juxtaposition and working-through as pedagogical strategies in order to begin thinking about how to live in dark places.

\section{Place-Based Pedagogies}

Since the early 2000s many environmental and social justice education scholars have converged around the notion of 'place'. Place-based pedagogies ${ }^{\mathrm{i}}$ are an index for a heterogeneous group of educational theories and practices that seek to 'go local' by foregrounding our immediate experience of interconnectedness with the human and the morethan-human in local communities (Gruenewald 2003a, 2003b; Smith 2007; Hill 2013). Although precise definitions vary, the concept of place in place-based pedagogies refers to a bounded symbolic, social and material domain, to which humans are emotionally attached, and the meanings of which are constitutive of their identities (Kudryavtsev, Stedman \& Krasny 2012, 230-233; Garrard 2010; Bonnett 2013; Wattchow \& Brown 2011, xxi). Place evokes notions of an immediate, deeply meaningful experience and imbuement with the more-than-human world (Hill \& Brown 2014, 228; see also Nicol 2014; Thorburn \& Marshall 2014). Subsequently, pedagogies of place highlight the importance of teaching 'bymeans-of-an-environment' in order to gain an understanding of the inextricable connection of 
the human with the more-than-human and to cultivate solidarity towards them (Mannion, Fenwick \& Lynch 2012, 803).

Recognizing these various modalities, David Gruenewald (2003a) provides a typology of place in five dimensions: The first is the perceptual dimension wherein place is understood phenomenologically as "the ground of direct human experience” (623). Gruenewald argues that in this dimension "people are capable of perceiving places and learning from that direct experience" and that "our ability to perceive places can be either thwarted or fostered by educational experience” (625). The second dimension of place is sociological: "place is where the world manifests itself to human beings” (625). Place in this modality is understood as a social construct that is produced and reproduced through culture. Third, places are ideological; that is, they instantiate "ideologies and relationships of power" (628). Fourth, and closely associated to the third dimension, places are political as in forming social identities. And finally, places are ecological. This dimension acknowledges the dependency of the human on the more-than-human lifeworld, the limits thereof and the spectrums of diversity that not only should be preserved, but that make life itself possible (633-636).

The categories of 'place' and 'local' also need an outside, a contrastive space in order for them to make sense. In other words, there must also be spaces that are not 'places'. This division gives place-based pedagogies their critical edge as the latter spaces pose a host of problems that these pedagogies seek to address. This is especially so in discourses employing critical pedagogy and/or social justice theories, where these other spaces are often characterized with prefixes 'colonial', 'global' and 'capitalist'. Accordingly, global capitalist logic produces ways of ordering and mobilizing human and more-than-human communities into standardized, monocultural spaces of production and consumption, thereby dissolving traditional cosmologies, values and ways of life that may have upheld a balance with the 
surrounding more-than-human community (Gruenewald 2003a, 2003b; Hill \& Brown 2014; McInerney, Smyth \& Down 2011; Wattchow \& Brown 2011).

Following this logic of uprooting and mobilization, modern schools have inculcated modes of splitting human experience into different schooling subjects and organizing them into isolated grids of time and space, which further dissolve the relationship with the local (McInerney, Smyth \& Down 2011). As a result, ecological problems like global warming may become isolated and intellectualized by framing them in abstract biological and geographical discourses and by dealing with decontextualized macro-scale concerns that have little to do with how a student might experience their immediate human and more-than-human community (Graham 2007; Smith 2007).

In sum, the concept of place in place-based pedagogies is often connected to notions of transformative experiences of connectedness, social justice and sustainability, while simultaneously constructing opposing notions of alienation, instrumentalism, and a compartmentalizing orientation to education (see e.g. Hill \& Brown 2014).

Yet many approaches in place-based pedagogies have also sought to problematize the very notion of 'place' and the meaning of 'local' (McInerney, Smyth \& Down 2011; Stevenson 2007; Johnson 2012; Ruitenberg 2005) as these may sometimes inadvertently smuggle in universalist, decontextualized and de-materialized meanings. Moreover, some critics have pointed out that the relationships between what are considered 'local' and 'global', 'culture' and 'nature' need to be more carefully traced in order to understand current economic and ecological problems (Gruenewald 2003a; Bowers 2008; Nespor 2008; McIerney 2011, 9-11; Nakagawa \& Payne 2014, 149-150). This is especially the case for settler colonialism wherein an anthropocentric, racialized, gendered and capitalistic conception of place has 
violently marginalized, inferiorized and supplanted other understandings of place (Seawright, 2014; see also Tuck, McKenzie \& McCoy, 2014; Korteweg \& Russell, 2012).

In recent new materialist discourses of environmental education in particular, place has come to indicate a heterogeneous set of material and symbolic trajectories and becomings that constitute reciprocal relations (Mannion, Fenwick \& Lynch 2012, 793-794; Clarke \& Mcphie 2016; Gough 2016; Clarke 2017).

What is persuasive in these conceptualizations is their problematization of 'place' as a circumscribed site of identifying ecological concerns, pedagogical initiatives to be taken, and the influences that education has upon the human and the more-than human environment. Moreover, they also resist holistic and systemic arguments (Weakland 2012) about place and make undecided and unstable the difference between local and global, nature and culture (Clarke 2017, 312).

While we heartily acknowledge the vast contributions that have been made in these problematizations of place, we sense that there is there is still space for elaboration in the different stipulations of place in the extant discourses of place-based pedagogy; that is, something that would account for the aforementioned hauntologically unsettling nature of experiencing global warming. For this we turn to Timothy Morton's conceptions of dark ecology and hyperobjects. Rather than engaging with a detailed commentary on his works, we use these two concepts as incitements to unpack the concept of the uncanny in order to ferret out its significance in conceptualizing place in environmental education research. While the uncanny aspects of these two concepts resonate somewhat with Gruenewald's (2003a) aforementioned dimensions of place, we focus here on how it unsettles the first and the last - the perceptual as connecting to a place with our immediate experience, and the ecological as signifying the more-than-human lifeworld. We argue that Morton's thoughts 
further the post-stucturalist and new materialist critique of bounded, stable places through introducing an ontology of finitude, withdrawal and excess.

\section{The Uncanny}

Morton argues that global warming discloses that what was once understood as a morally neutral and cyclical background (read: nature) has gained a capricious agency, confounding our ethical aptitudes (2013; see also Jenkins 2013). Our particularly ‘modern’ way of differentiating human and non-human and culture and nature have been thrown into disarray, haunting our lived experiences of place:

Space in this sense [i.e. the Euclidean concept of space as abstract and stable] has collapsed, and place has emerged in its truly monstrous uncanny dimension, which is to say its nonhuman dimension. How? Now that the globalization dust has settled and the global warming data is in, we human find ourselves on a very specific planet with a specific biosphere... Our sense of planet is not a cosmopolitan rush but rather the uncanny feeling that there are all kinds of places at all kinds of scales... And these places, as the concept of spacetime, are inextricably bound up with different kinds of timescale... So many intersecting places, so many scales, so many nonhumans. Place now has nothing to do with good old reliable constancy. What has dissolved is the idea of constant presence: the myth that something is real insofar as it is consistently, constantly 'there.' (Morton 2016, 10)

With the dissolution of space as present, knowable and controllable, ecological experience today is inevitably uncanny. Here, Morton follows Heidegger's (2000) use of German das Unheimlich: the not-at-home, alienated, or wandering (Morton 2012, 11). Yet it is Freud's (1919) definition of the term that provides the most import: the uncanny as that what once seemed safe and familiar, but which has assumed an air of strangeness and foreboding 
(Morton 2012, 11-12) —like seeing an environmental catastrophe in the beautiful colour of a Finnish sunset. In other words, the experience of the uncanny results from a strange juxtaposition between things that, in the dominant cosmology, should have remained separate, like culture and nature, human and non-human, safe and dangerous (Saari 2018).

The concept of the uncanny also resonates with abjection, i.e. the repressed objects of our experience. When isolated and repressed contents surface in consciousness, they may shatter existing coordinates of reality, thereby inducing the experience of the uncanny. This is not only related to personal experience, but resonates also with collective ontological imageries that delimit our experience. The experience of the uncanny is indelibly etched in the philosophical Enlightenment tradition, which accentuates knowing, reason, lucidity, control and planning and, inversely, represses unreason, darkness and unknowing (Dolar 1991).

Consider global warming as something most of us would rather not think about: our lives and thoughts are often organized around isolating and insulating that ominous, uncontrollable, non-local reality into the ‘ecological unconscious' (Morton 2007). Engaging with global warming, therefore, requires sensitivity to forms of recoil, isolation, and 'passionate ignorance' that often emerge in our encounters with ecological catastrophes and degradation (Nicholsen 2002; Norgaard 2011; Dodds 2011). These aspects, we argue, are the aspects often absent from place-based pedagogies. And this is where Morton's work on hyperobjects and dark ecology come to bear for environmental education researchers.

\section{Dark Ecology}

Morton (2016) proposes ‘dark ecology’ as an ontological and ethical attunement to the uncanny event of global warming and our ecological reality more generally. Dark ecology, in 
the shortest of definitions, is a model of ecological awareness (Morton 2016, 5). And ecological awareness, in short, is coexistence (Morton 2010, 2). And coexistence, in short, is dark (Morton 2010, 15-16). Dark, as we understand it, alludes to at least three interconnected threads that run throughout Morton's work. In the first place it presses up against the “positive, sunny 'Zippity Doo Da'” sentimentality that has characterized 'green’ environmentalist thinking: one that says, “we're all interconnected; and isn’t it wonderful!” Morton posits that this sunny, holistic, hearty and healthy sentimentality occludes other dimensions like negativity, ambiguity, darkness, irony and fragmentation (Morton 2010, 16). Dark in this first understanding reveals the 'other' side, the shaded side, of ecological awareness and coexistence.

Dark refers also to a veil of unknowing as opposed to the anthropocentric models of knowing and mastery that characterizes environmental phenomena, aspects of which are present even in—actually, especially in—scientific knowledge about our environment; that is, the more we acquire data about global warming, for example, the more ambiguous and uncanny it becomes. It defies, in other words, our inherited and common sense notions of space, time and matter (Morton 2010, 17), which we will elaborate on in further detail in our discussion on hyperobjects below.

In the third place, dark is explicitly connected to object-oriented ontology (OOO), which for our purposes is a philosophy that highlights finitude and withdrawal. Finitude refers here to our inability to access the thing in itself: "when I try to find the thing in itself, what I find are thing data, not the thing in itself. And I grasp that data in such a way that a thing does not (meaningfully) exist (for me) outside the way I... correlate the data” (16). This irreducible rift, according to OOO, between thing and appearance reveals the "profoundly limited and incomplete” access of human knowledge, which is characteristic of nonhuman knowing as 
well (17). This epistemic finitude follows a withdrawn and excessive ontology wherein “things exist in a profoundly ‘withdrawn’ way: they cannot be splayed open and totally grasped by anything whatsoever, including themselves” (16). Reality, according to OOO, exists outside the mind, yet, and this is crucial, we cannot know it except for "indirect, allusive, or vicarious means” (Harman 2016, 17). In short, we know only through a glass darkly as things withdraw and remain in excess of any and every entity's access of any thing.

The advent of global warming prominently draws our attention to the withdrawn character of objects as a ghostly "pres/absence” that we must attempt to come to grips with as educational researchers (Caputo 2016b, 116). How these three aspects of Morton’s dark ecology matter for place-based pedagogy in the event of hyperobjects is the contribution we would like to provide for environmental education research. But before we discuss this, we will need to elaborate on how Morton describes hyperobjects.

\section{Hyperobjects}

As we mentioned above, Morton sees global warming as an event that haunts our stabilized notions of place. As such, global warming is understood as a hyperobject —an entity massively dispersed in space and in time. Global warming is by no means the first or only existing hyperobject-Morton mentions styrofoam cups, radioactive plutonium, and the Florida Everglades among a variety of examples—but it condenses for us the multiple temporal and spatial scales and ethical concerns imbued in them in relation to our experiences of places. Hyperobjects can be identified by the following five qualities: (Morton 2010; 2013a, 2013b): First, hyperobjects are viscous: they stick, bleed and stretch despite our attempts to categorize and insulate them. The more you try to study them, the more strange they become. The more you try to externalize and compartmentalize them, the more you find 
your own self being tangled in them. Second, hyperobjects are non-local: they are not reducible to a separate place and time but are indeterminately dispersed, as the above example of the red sunrise serves to testify. Third, hyperobjects are temporally undulated: they are time-stretched to a vast extent, assuming multiple rhythms. A hyperobject like global warming not only covers planetary distances but industrial revolutions, the nature of the evolutionary process itself, and the migratory and mass extinction patterns of both flora and fauna to name but a few: "Recall the three timescales of global warming: the horrifying, the terrifying, and the petrifying — five hundred, thirty thousand, and one hundred years respectively. These very large finitudes collapse my cliched ideas of time from within” (Morton 2013a, 136). Fourth, hyperobjects are phased: they are transdimensional such that we can only ever see a part of them while other parts withdraw; that is, they "occupy a high dimensional phase space that makes them impossible to see as a whole on a regular threedimensional human-scale basis” (Morton, 2013a, 70). The problem with using weather and climate synonymously is a helpful illustration of this: climate is the transdimensional system of which weather is its sensual impression (74). The one we see and feel—and even its raindrop exceeds our access — while the other withdraws when we try. Lastly, hyperobjects are interobjective: they form a heterogeneous human and non-human assemblage and are not reducible to but exceed the human-world correlation. This means they are never experienced directly but are always mediated or translated through some entity's access and yet they have a history of their own apart from any human, non-human mediation (Morton 2013a, 27-95).

In sum, Morton (2011, 216-217) characterizes hyperobjects as ‘strange strangers’; that is, groups of objects that are strangers even to each other, which also conveys the idea that they are irreducible in our attempt to make them intelligible as in our totalizing and homogenizing concepts of 'nature' or 'place' (see also Wark 2015, 200). This radical alterity inherent to 
hyperobjects runs contrary to the theories of 'relationality' and 'environmental' views that characterize ecological spaces as (tacitly) homogenous, knowable planes or 'ecosystems' (Harman 2005; Morton 2011, 2012). The concept of hyperobjects brings to the surface the short-circuits, abjects and sources of anxiety inherent in ecological awareness, thereby challenging our notions of 'place' as bounded, identifiable and (intellectually) safe.

\section{A Dark Pedagogy of Place}

Accordingly, we argue that Morton's theory of dark ecology and hyperobjects opens up an understanding of the uncanny aspects of place in environmental education, especially with regard to its perceptual and ecological dimensions. We condense this in the form of the following theses:

1) The impossibility of drawing geographic and temporal contours around the notion of 'place', leading to conceptualizing and researching 'place' in terms of excess and non-locality rather than an organic and romantic whole as is usually the case;

2) Re-imagining the ethical values and aims of pedagogies of place in terms of an irreducible alienation and experiences of the uncanny rather than a return to blissful harmony and belonging.

Using the dark qualities of global warming, we argue that these registers can be activated with the conceptual strategies of juxtaposition and working-through.

\section{Juxtaposition}

The Western imaginaries of nature and the more-than-human environment have for long provided a grid of intelligibility for environmental education: organizing identities and differences therein and drawing external borders with the human and the cultural. This, in turn, has often framed place-based approaches and outdoor education in tracing untrammeled 
spaces for 'nature experiences' that express holistic and immersive contact with nature (Bonnett 2004, 2007; Clarke 2017, 308-309).

This imagery is founded on a metaphysics positing the existence of nature-as-a-whole: as a clear-cut organic or systemic unity (Clarke 2017, 309). In the event of hyperobjects, the metaphysics of the 'whole' is contrasted with an ontology of withdrawal, excess and out-ofjointedness - being as always more than what we are able to capture in conceptual classification or perceptual experience. Being, in other words, does not constitute a container holding homogeneous matter. Instead, it is a plethora of objects that are inaccessible to each other and therefore escape classification and reduction into an organic whole (Morton 2007; Harman 2005, 251). This is why Morton (2007) demands that we do away with the concept of nature altogether, as it only buttresses the unacknowledged, taken-for-granted spacing of mainstream ecology.

Moreover, Morton claims that our notions of space and nature and solidarity towards 'nature' are founded on a metaphysics of presence (Morton 2016a) or an ontological figure-ground distinction (Morton 2007)—equating what is near, immediately perceived and controllable with what is 'true' and 'real', and as such, worthy of our solidarity. As Massey (2004) notes, often our notions of solidarity and empathy follow certain 'geographies of responsibility' that are structured like concentric circles going from the parent-child relationship as the nucleus of caring to the local and to the global. Yet, when encountering the uncanniness of hyperobjects, the coordinates that organize things into of near-far, local-global become ambiguous (Morton 2007, 2016).

We argue for conceptual strategies of disrupting the fantasies of organic wholeness in the uses of nature, environment or place in education. Juxtaposition (Morton 2007, 143-150) 
means bringing into uncanny proximity, play or comparison objects and events that are conventionally seen as distant, incompatible or altogether abject in environmental discourse (see also Saari 2018). This aligns closely with Mitchell Thomashow’s (2002) call to cultivate an open-ended imagination of places outside of either those regarded as 'nature' or planned and meticulously designed ‘learning environments’ (see also Rautio 2014). This might include broadening the focus from pristine, 'natural' places in place-based pedagogy to include their crossings and layerings with urban, industrial and polluted spaces (Garrard 2010).

This is especially the case when dealing with hyperobjects like global warming where juxtaposition articulates place-based pedagogy without place being bounded and subject to intellectual mastery. Juxtaposition may start with an immediate perceptual experience of seeing a beautiful red sunrise, for example, and moving on from there to studying climate science, the advent of the human species, the industrial revolution, and then coming to realize the geological force our species has become and our own individual implication in it (Morton 2016, 7). There are no privileged space-times in nature: here, too, the uncanny is everpresent.

Juxtaposition as a pedagogical strategy resonates with Jason Wallin’s (2015) “pedagogical dark ecosophy” wherein we recognize that the "forces of planetary decay, mutation, and violent upheaval [are] obfuscated by education's subjugation of the unconscious in an image of romantic humanism” (139, 142-143; see also Wallin 2014). Wallin argues that "education must become capable of unthinking anthropocentrism by taking seriously both the collapse of human and nonhuman 'things' as well as that which is already inhuman within the human” (142). The merit of tethering the strategy of juxtaposition with Wallin's dark ecosophy is 
their mutual interest of bringing encounters with abjects into the fore of pedagogical experiences, and certain forms of art carry unparalleled potential in this regard.

Consider as an example the recent "Ice Watch" installation in Paris by Icelandic artist Olafur Eliasson and geologist Minik Rosing where "Ice Watch" is meant as a double entendre: the clock-like shape of icebergs on a Parisian street refers to the haunting time scales of global warming and also the haunting reality of watching the ice melt right in front of the viewer. And yet as Eliasson explains, "It is a mistake to think that the work of art is the circle of ice-it is the space it invents” (Zarin 2015). Inventing spaces like “Ice Watch” are powerful pedagogical tools for juxtaposition and dark ecosophy that have the potential to draw to the surface aspects of our haunting ecological unconsciousness, or those aspects we intentionally suppress and would rather not dwell on.

In sum, the particular aim of juxtaposition in the mode of dark ecology is not to make these events fit into a larger scheme of things, but to highlight the inexorable uncanniness of place. It should also be noted that dark ecology differs from some Latourian applications of tracing a 'hybrid' (Latour 1993) or an actor-network (Latour 2005). As mentioned above, objects that are inherently strange to themselves cannot compose an empirically characterizable network. Instead they express non-localizable gaps and disparities.

\section{Working-through}

Global warming is an event which reveals a deep ambiguity not only in the places outside us, but also questions our own possibility of dwelling within them: there is an uncanny undecidability between the subjective and the 'objective', the human and the non-human, the far away and the deeply personal. Our own existence is, in a strange way, imbued with that 
which always has remained at a comfortable distance as impersonal and non-human (Morton 2013).

Morton refers to the literary and cinematic trope of noir to characterize this dramatic turn. In a typical film noir, the protagonist detective all the while looking for the murderer finds out that he himself is the culprit (Morton 2016, 9). In a similar fashion, researching and teaching about global warming — investigating melting ice caps, CO2 and methane emissionsinevitably closes in on the sensitive area of our own implication in it. However, this does not mean singling out ourselves as being in control of the environment, but instead the uncomfortable discovery of finding ourselves inside a massively dispersed hyperobject, which we cannot control.

Ecopsychoanalytic theorists have recently pointed out the 'climate trauma' inflicted by the uncomfortable reality of global warming and our own implication in it. With global warming they argue that we are not only having difficulty relating to a 'place', but we are also, to some extent, in danger of losing some of the basic coordinates of experiencing reality like planning ahead, remembering and the emotional attachments that bear on our environments (Orange 2017, 14-18). The uncanny, disorienting experience of global warming may lead to both personal and collective defensive strategies of denial, splitting, compartmentalization, and emotional freezing (Dodds 2011; Lertzman 2015; Orange 2017; Weintrobe 2013). What is often seen as lacking in our relation to ecological concerns is the ability to express loss and the crippling empathy of suffering, and the guilt of our own implication in ecological degradation (Orange 2017, 55-56; Lertzman 2015). 
Paying close attention to the way spatial disorientation is imbued with manifold psychic distresses, Glenn Albrecht coined the term solastalgia in order to name the longing for places where a person had once felt at home, but have since been experienced as disorientation, senses of homelessness, depression, memory loss, and various modes of estrangement from self and others. Albrecht identifies this among indigenous people displaced by colonial settlers as well as those Americans born and grown up in industrial environments who have felt the lack of connection to our ever changing geographical environment (Albrecht 2005, 43-44).

Albrecht's solastalgia is palpable in Gaston Gordillo’s (2014) ethnography of the Andes where the livelihoods of the rural poor are obliterated by companies creating soy fields in the area. Fields are filled with rubble from bulldozed infrastructures from different eras and cultures, and this rubble becomes a metaphor for the abjects and debris constantly produced by global capital. Gordillo notes how the operation of agribusiness in the area together with global capital and the layers upon layers of violent colonial rule and the deep anxiety and mental distress among the peasant population destroys the gaucho way of life, obliterates markers that provide geographic orientation, and suppresses their personal and shared memories and identities.

Bodnar (2008) and Lertzman (2015) attest that strong emotions, affects and identity are mutually embedded not only with humans, but also the more-than-human world. Lertzman claims that "certain objects are like 'psychic keys' through which we articulate ourselves” (Lertzman 2015 88). This is documented in her study of Green Bay inhabitants: their life histories amid industrialisation and ecological degradation in the area provide insights into how global ecological and economic trajectories are imbued in psychic trauma that is "shot 
through with powerful and inchoate affective investments, memories, desires and losses” (101). In her interviews, Lertzman found a recurring narrative of a loss of innocence, purity and sanctuary in increasing ecological degradation. This innocence was projected into elements of the environment—clear blue skies, sunlight reflected in a lake surface (78-81). When these elements are taken away, the experience of anxiety, loss and disorientation becomes pressing, yet difficult to articulate.

Studies like this show that uncanny experiences of places may engender denial, projection and isolation, which are not only psychological but also political phenomena, bearing on the questions of social justice and environmental concerns. Acknowledging and expressing difficult experiences of dark places rather than suppressing them in education is crucial for ecological engagement. Dodds (2011, 69, 100-101) uses the analogy with the psychoanalytic practices of 'working-through' as necessary in thinking about the task of overcoming anxiety and guilt in relation to ecological disasters. This term refers to the psychoanalytic interpretive 'work', the articulation of one's own thoughts, memories, dreams and emotions, by the analysand. The 'through' here also may be read as a direct confrontation, naming and being with, rather than avoiding, suppressing or even trying to 'solve' anxiety caused by the uncanniness of place (see also Lertzman, 2015, 101, 129-130).

This finds resonance in the transformative aspects of dark ecology, which traces out the shifts from dark-depressing to dark-sweet that transpire in the articulation of the uncanny aspects of ecological experience (Morton 2016a, 160). Without denying the embodied, psychological or political benefits that 'nature experiences' may have, a dark ecological ethics of workingthrough might contribute in highlighting a certain uncanniness as an inherent quality of existence, not only with humans, but objects in general (see Morton 2010b, 255-256). This 
approach will not do away with our predicament of 'alienation' from, or uncanny relation to, our environment, as in seeking a holistic experience of nature. Instead it changes our attunement to the predicament (Morton 2016b, 264) by creating pedagogical environments where working-through can take place; where loss, unknowing, and anxiety can be witnessed and articulated instead of denial or repression (see also Lertzman 2014, 150). This finds resonance in Rebecca Martusewicz’s (2015) call to 'let our hearts break:' to articulate the grief and anxiety over the injustice and pain inflicted on the more-than-human world and to assume responsibility for it (see also Pihkala 2017; Morton, 2016, 161).

This is point is uniquely and poignantly drawn out in Wallin's (2015) analysis of zombie narratives that seem to be only gaining in popularity: “Zombie-life,” he writes, “deterritorializes the anthropocentric facialization of the planet by diagramming an unthought dark ecology;" Wallin argues that "the subterranean ecology fabulated in zombie fiction questions not only how a life might go, but also what things and of what things might think where we are not [and one] in which humans are divested of their presumed status as dominant planetary actants transcendent to material life” (p. 139). Speculative fictions like zombie narratives and dystopian futures can be a helpful mode of beginning to work-through the social and psychic imaginaries in which we humans are ontologically and ethically privileged and prioritized.

This also points to the need of dealing with the ambivalence and ambiguity of experiencing place — the undecidability of the locus of responsibility, personal and global, human and more-than-human nature of environmental crises and the mixed affects these crises engender. One can be a beneficiary of a economic system that produces jobs, income and a decent standard of living, while sustaining grave social injustices and inflicting ecological damage 
(Lertzman 2015). If our affects, desires, hopes and fears are projected into material and morethan-human environments, working-through can also take place in the form of recognising sites of mourning, ambiguous affects and the corresponding senses of injustices (150). And all the while recognizing these emotions as uncanny and ambivalent rather than splitting them into good and bad or local and global.

Our point here is not simply to dwell on what is repugnant or horrendous, but to enable engagement by not sustaining a culture of denial that occludes these essential aspects. Ideas from place-based pedagogies are already used with arts education—visual and performing arts and drama — to articulate a sense of hope, fear, or responsibility in relation to global warming (see e.g Popov 2018). These can give expression to aesthetic and emotional aspects of the uncanny and sustain rather than efface ambiguity like the "Ice Watch" installation in the streets of Paris.

\section{Conclusion}

Throughout this article we have been referring to hyperobjects like global warming as events, and as is the nature of events, they tend to shock and or undermine our prevailing conceptual systems or frameworks of which our expectations are found lacking (Caputo, 2012; 2016a; 2016b). Our commonplace understandings of place are destabilized by the haunting events like global warming thereby revealing the uncanny and dark dimensions of place. Understanding the nature of hyperobjects as an event has consequences for thinking about and living into 'place’ in place-based pedagogies.

We should not go without mentioning that the darkness we are proposing in this study is not intended to inculcate guilt, depression or apathy in the face of an overbearing event like 
global warming. Instead, we propose that it opens up a heretofore undisclosed dimension for thinking about places as deeply uncanny. Accordingly, this thinking problematizes two extant ways of addressing ecological threats in environmental education: First is the tendency to see ecological degradation as a result of our alienation from 'nature', which is conveyed in the practices of cultivating holistic 'nature experiences' in place-based pedagogy as a cure. As discussed above, the notion of place as deeply uncanny is founded on the realization that more we investigate a place, the more weird it becomes as it reveals the infinite multiplicity of temporal rhythms and spatial trajectories. Our strategy of juxtaposition aims to disrupt this sense of alienation that is produced in a 'nature-as-whole' ontology. Instead, because of the advent of hyperobjects, reality is revealed as excessive and disjointed, which calls for an open-ended imaginary that can live in the conceptual cracks and fissures that the haunting event of global warming creates for our experience of living into dark places.

The other tendency is to understand educational responses to ecological threats as an issue of the correspondence of knowledge to attitudes to action (see also Lertzman 2015, 146-149). If students are witnesses to environmental degradation in their local community and begin to understand the effect their actions have then this should motivate them to change their habits into more sustainable ones. While this might sound like a straightforward way of engaging with environmental education, this has the tendency to obscure the anxiety and denial that occurs when faced with the reality of global warming and our complicity in it. This model of immediacy "wants to be relieved of the burden of anxiety and uncertainty” that ecological threats pose, but it is precisely these uncanny aspects of place that we need to learn how to live with if we are to take coexistence seriously (Morton, 2018, 18). It is for this reason that we suggest the pedagogical strategy of working-through the senses of loss and uncertainty, denial and anxiety that hyperobjects produce. The realization that we are "part of an entity 
that is now a geophysical force on a planetary scale," like the detective that is the criminal in a noir film, highlights our entanglement and culpability that we cannot gloss over in our attempt to do something about it (Morton 2016, 9, 29). Instead, working-through our complicity and bearing its burden is a phase we cannot go without confronting in our efforts at coexistence in the uncanny multiplicity of places (9-12). Both of these strategies are pedagogical possibilities for hopefully opening up a conversation on how to live in the dark places that are haunted by the reality of hyperobjects (Morton, 2018, 15). 


\section{References}

Albrecht, G. 2005. ”'Solastalgia'. A New Concept in Health and Identity”. PAN: Philosophy Activism Nature, (3), 41-55.

Bodnar, S. 2008. ”Wasted and Bombed: Clinical Enactments of a Changing Relationship to the Earth”. Psychoanalytic Dialogues, 18(4), 484-512.

Bonnett, M. 2007. ”Environmental Education and the Issue of Nature”. Journal of Curriculum Studies 39 (6): 707-721.

Bonnett, M. 2004. ”Lost in Space? Education and the Concept of Nature”. Studies in Philosophy and Education 23(2): 117-130.

Bonnett, M. 2013. ”Sustainable Development, Environmental Education, and the Significance of Being in Place”. Curriculum Journal 24(2), 250-271.

Bowers, C. A. 2008. "Why a Critical Pedagogy of Place is an Oxymoron”. Environmental Education Research 14 (3): 325-335.

Caputo, J. D. and Dickinson, T. W. 2012. ”Education as Event: A Conversation with John D. Caputo”. Journal for Cultural and Religious Theory, 12 (2): 25-46.

Caputo, J. D. 2016a. Truth: The Search for Wisdom in the Postmodern Age. London: Penguin Books.

Caputo, J. D. 2016b. ”Teaching the Event: Deconstruction, Hauntology, and the Scene of Pedagogy”. In The Pedagogics of Unlearning, edited by Aidan Seery and Eamonn Dunne, 111-130. Earth, Milky Way: Punctum Books.

Clarke, D. A. G. 2017. “Educating Beyond the Cultural and the Natural: (Re)Framing the Limits of the Possible in Environmental Education,” In Reimagining Sustainability in Precarious Times, edited by K. Malone, S. Truong, and T. Gray, 305-318. London: Springer.

Clarke, D. A. and J. Mcphie. 2016. ”From Places to Paths: Learning for Sustainability, 
Teacher Education and a Philosophy of Becoming”. Environmental Education Research, 22 (7): 1002-1024.

Dodds, J. 2011. Psychoanalysis and Ecology at the Edge of Chaos: Complexity Theory, Deleuze/ Guattari and Psychoanalysis for a Climate in Crisis. New York: Routledge. Dolar, M. 1991. ”"I Shall Be with You on Your Wedding-Night": Lacan and the Uncanny.” October, 58: 5-23.

Freud, S. 1919. “The ‘Uncanny”. In Standard Edition 17, 217-256. London: Hogarth Press. Garrard, G. 2010. ”Problems and Prospects in Ecocritical Pedagogy”. Environmental Education Research, 16(2): 233-245.

Gordillo, G. R. 2014. Rubble: The Afterlife of Destruction. Durham: Duke University Press. Gough, N. 2016. ”Postparadigmatic Materialisms: A “New Movement of Thought” for Outdoor Environmental Education Research?” Journal of Outdoor and Environmental Education, 19: 51-65.

Graham, M. A. 2007. ”Art, Ecology and Art Education: Locating Art Education in a Critical Place-Based Pedagogy”. Studies in Art Education, 48: 375-391.

Gruenewald, D. A. 2003a. ”Foundations of Place: A Multidisciplinary Framework for PlaceConscious Education”. American Education Research Journal, 40: 619-654.

Gruenewald, D. A. 2003b. ”The Best of Both Worlds: A Critical Pedagogy of Place”. Educational Researcher, 32(4): 3-12.

Harman, G. 2005. Guerrilla Metaphysics: Phenomenology and the Carpentry of Things. Peru, IL: Open Court. Harman, G. 2016. Immaterialism: Objects and Social Theory. Malden, MA: Polity Press. Heidegger, M. 2000. Introduction to Metaphysics. New Haven: Yale University Press. 
Hill, A. 2013. ”The Place of Experience and the Experience of Place: Intersections Between Sustainability Education and Outdoor Learning”. Australian Journal of Environmental Education 29 (1): 18-32.

Hill, A. and M. Brown. 2014. ”Intersections between place, Sustainability and transformative outdoor experiences”. Journal of Adventure Education \& Outdoor Learning 14 (3): 217-23.

Jenkins, W. 2013. The Future of Ethics: Sustainability, Social Justice, and Religious Creativity. Washington, DC: Georgetown University Press.

Korteweg, L., \& C. Russell. 2012. ”Editorial: Decolonizing + Indigenizing = Moving Environmental Education Towards Reconciliation”. Canadian Journal of Environmental Education 17: 5-14.

Kudryavtsev, A., R. C. Stedman and M. E. Krasny. 2012. ”Sense of Place in Environmental Education”. Environmental Education Research 18 (2): 229-250.

Latour, B. 1993. We Have Never Been Modern. Cambridge (Mass.): Harvard University Press.

Latour, B. 2005. Reassembling the Social: An Introduction to Actor-Network-Theory. Oxford: Oxford University Press

Lertzman, R. 2014. Environmental Melancholia: Psychoanalytic Dimensions of Engagement. New York: Routledge.

Massey, D. 2004. ”Geographies of Responsibility”. Geografiska Annaler: Series B, Human Geography 86 (1): 5-18.

Mannion, G., A. Fenwick, and J. Lynch. 2012. “Place-Responsive Pedagogy: Learning From Teachers’ Experiences of Excursions in Nature.” Environmental Education Research 19 (6): 1-18. 
Martusewicz, R. A. 2015. ”Letting Our Hearts Break: On Facing the "Hidden Wound" of Human Supremacy”. Canadian Journal of Environmental Education 19: 31-46.

McInerney, P., J. Smyth, and B. Down. 2011. ”'Coming to a Place Near You?’The Politics and Possibilities of a Critical Pedagogy of Place-Based Education”. Asia-Pacific Journal of Teacher Education 39(1): 3-16.

Morton, T. 2007. Ecology Without Nature: Rethinking Environmental Aesthetics. Cambridge (Mass.): Harvard University Press.

Morton, T. 2010a. The Ecological Thought. Cambridge (Mass.): Harvard University Press.

Morton, T. 2010b. “The Dark Ecology of Elegy”. In Oxford Handbook of Elegy, edited by K.Weisman, 251-271. Oxford: Oxford University Press.

Morton, T. 2011. ”Sublime Objects”. Speculations 2: 207-27.

Morton, T. 2012. ”The Oedipal Logic of Ecological Awareness”. Environmental Humanities 1(1): 7-21.

Morton, T. 2013a. Hyperobjects: Philosophy and Ecology After the End of the World. Minneapolis, MN: University of Minnesota Press.

Morton, T. 2013b. ’Poisoned Ground: Art and Philosophy in the Time of Hyperobjects”. Symploke 21(1): 37-50.

Morton, T. 2016. Dark Ecology: For a Logic of Future Coexistence. New York, NY: Columbia University Press.

Morton T. 2018. Being Ecological. London, UK: Pelican Books.

Nakagawa, Y., and Payne, P. G. 2014. ”Critical Place as a Fluid Margin in Post-Critical Environmental Education”. Environmental Education Research 21 (2):149-172.

Nicholsen, S. W. 2002. The Love of Nature and the End of the World: The Unspoken Dimensions of Environmental Concern. Cambridge: MIT Press.

Nicol, R. 2014. "Entering the Fray: The Role of Outdoor Education in Providing Nature- 
Based Experiences That Matter”. Educational Philosophy and Theory 46 (5): 449461.

Norgaard, K. 2011. Living in Denial: Climate Change, Emotions, and Everyday Life. Cambridge: MIT Press.

Orange, D. M. 2017. Climate Crisis, Psychoanalysis, and Radical Ethics. New York: Taylor \& Francis.

Pihkala, P. 2017. ”Environmental Education After Sustainability: Hope in the Midst of Tragedy”. Global Discourse 7 (1): 109-127.

Popov, B. 2018. ”The Uncle Vanya Project: Performance, Landscape, and Time”. In Art, EcoJustice, and Education: Intersecting Theories and Practises, edited by R. Foster, J. Mäkelä and R. Martusewicz, 82-94. New York: Routledge.

Rautio, P. 2014. ”Mingling and Imitating in Producing Spaces for Knowing and Being: Insights From a Finnish Study of Child-Matter Intra-Action”. Childhood, 21(4): 461474.

Ruitenberg, C. 2005. ”Deconstructing the Experience of the Local: Toward a Radical Pedagogy of Place”. Philosophy of Education, 212-220.

Saari, A. 2018. ”The Experience of the Uncanny as a Challenge for Teaching Ecological Awareness” in Art, EcoJustice, and Education: Intersecting Theories and Practises, edited by R. Foster, J. Mäkelä and R. Martusewicz, 36-46. New York: Routledge.

Seawright, G. 2014. Settler traditions of place: Making explicit the epistemological legacy of white settler colonialism for place-based education. Educational Studies 50: 554-572.

Smith, G. A. 2007. ”Place-Based Education: Breaking Through the Constraining Regularities of Public School”. Environmental Education Research, 13(2): 189-207.

Stevenson, R. B. 2007. ”Schooling and Environmental Education: Contradictions in Purpose and Practice”. Environmental Education Research 13(2): 139-153. 
Thomashow, M. 2002. Bringing the Biosphere Home: Learning to Perceive Global Environmental Change. Cambridge, Mass: MIT Press.

Thorburn, M. and A. Marshall. 2014. ”Cultivating Lived-Body Consciousness: Enhancing Cognition and Emotion Through Outdoor Learning”. Journal of Pedagogy 5 (1): 115132.

Tuck, E., M. McKenzie, \& K. McCoy, 2014. ”Editorial: Land education: Indigenous, postcolonial, and decolonizing perspectives on place and environmental education research.” Environmental Education Research 20 (1): 1-23.

Wallin, J. 2014. "Dark Pedagogy” in The Animal Catalyst: Towards Ahuman Theory, edited by P. MacCormack, 145-162. London: Bloomsbury.

Wallin, J. J. 2015. Dark Posthumanism, Unthinking Education, and Ecology at the End of the Anthropocene. In N. Snaza and J. A. Weaver (Eds.), Posthumanism and Educational Research (pp. 134-147). New York: Routledge.

Wark, M. 2015. Molecular Red: Theory for the Anthropocene. London: Verso.

Wattchow, B., and Brown, M. 2011. A Pedagogy of Place: Outdoor Education for a Changing World. Monash: Monash University Publishing.

Weakland, J. P. 2012. “Queering Ecology: Interrogating 'Seductions to Organic Wholeness' in Popular Environmental Rhetoric.” In Learning for Sustainability in Times of Accelerating Change, edited by A. Walsh \& P. Corcoran, 121-132. Wageningen: Wageningen Publishers..

Weintrobe, S. 2013. “The Difficult Problem of Anxiety in Thinking About Climate Change”. In Engaging with Climate Change: Psychoanalytic and Interdisciplinary Perspectives, edited by S. Weintrobe, 33-47. New York: Routledge.

Zarin, C. 2017. “The Artist Who is Bringing Icebergs to Paris.” The New Yorker, December 5, 2015. 
i While acknowledging the plethora of these approaches—place-based education, place-responsive education, and a critical pedagogy of place, to name but a few-we refer to them here as "place-based pedagogies" for the sake of simplicity. 